\title{
Pengaruh Perbedaan Intensitas Cahaya Terhadap Kelimpahan Arthropoda di Perairan Desa Tambakpolo, Demak
}

\author{
Arrico Fathur Yudha Bramasta*, Wilis Ari Setyati, Ria Azizah Tri Nuraini \\ Departemen IImu Kelautan, Fakultas Perikanan dan IImu Kelautan, Universitas Diponegoro \\ JI. Prof. H. Soedarto S.H, Tembalang, Semarang, Jawa Tengah 50275 Indonesia \\ ${ }^{*}$ Corresponding author, e-mail :arrico.yudha@gmail.com
}

\begin{abstract}
ABSTRAK: Zooplankton merupakan organisme laut yang memiliki peran dalam rantai makanan di laut. Zooplankton berperan pada tingkat energi kedua yang menghubungkan produsen (fitoplankton) dengan konsumen tingkat tinggi. Penelitian ini bertujuan untuk mengetahui komposisi dan struktur komunitas Arthropoda dengan dua perbedaan intensitas cahaya (300 lux dan 2000 lux). Penelitian ini dilakukan menggunakan metode purposive sampling yang terdiri dari tiga stasiun. Pengambilan sample zooplankton dilakukan dengan bantuan plankton net yang ditarik kapal tiga kali pengulangan. Berdasarkan penelitian ditemukan 5 genus yaitu Calanus, Paracalanus, Sergia, Eucalanus dan Candacia. Genus yang paling banyak ditemukan adalah Calanus dan Sergia. Kelimpahan Arthropoda tertinggi terdapat pada Stasiun 1 dengan intensitas 2000 lux sebesar 8.492 ind/L dan terendah pada Stasiun 3 dengan intensitas 300 lux sebesar $2.286 \mathrm{lnd} / \mathrm{L}$, hal ini diduga karena pengaruh gaya fototastik positif dari fitoplankton terhadap sumber cahaya yang direspon baik oleh zooplankton khususnya Arthropoda sebagai sumber makanan. Tingkat keanekaragaman $\left(H^{\prime}\right)$ Arthropoda di perairan tersebut termasuk dalam kategori rendah, indeks keseragaman (E) dalam kategori rendah, dan terdapat dominansi $(\mathrm{C})$.
\end{abstract}

Kata kunci: intensitas cahaya; kelimpahan; struktur komunitas; arthropoda

\section{The Effect of Different Light Intensity to Abundance of Arthropode in Tambakpolo, Demak}

ABSTRACT: Zooplankton are those organisms which have a role in food-web in aquatic ecosystems. Zooplankton as second trophic level organism whose connects producers (phytoplankton) with consumers at a higher trophic level. This research aims to know the composition and structure of the Arthropode community with two differences in light intensity (300 lux and 2000 lux). This research was done by using purposive sampling method which consists of three stations, by using a plankton net that was pulled by the boat. The results of the study found five genera namely Calanus, Paracalanus, Sergia, Eucalanus, Candacia. The most common genera are Calanus and Sergia. The highest abundance of Arthropode at Station 1 with an intensity 2000 lux is $8.492 \mathrm{ind} / \mathrm{L}$ and the lowest at Station 3 with an intensity 300 lux is $2.286 \mathrm{Ind} / \mathrm{L}$. The level of diversity $\left(H^{\prime}\right)$ of Arthropode categorized as low, the index of uniformity $(E)$ is categorized medium, the level of dominance $(C)$ is classified as high.

Keywords: light intensity; abundance; community structure; arthropode

\section{PENDAHULUAN}

Zooplankton merupakan organisme yang menempati posisi penting dalam rantai makanan dan kehidupan di perairan (Nontji, 2006). Zooplankton memiliki peranan sebagai konsumen tingkat satu di dalam rantai makanan dimana zooplankton memakan fitoplankton yang selanjutnya akan dimakan oleh organisme yang memiliki tingkatan lebih tinggi dalam rantai makanan, oleh karena itu zooplankton mampu menggambarkan karakteristik suatu perairan tersebut. Cahaya di perairan mempunyai pengaruh secara langsung maupun tidak langsung di lingkungan tersebut (FerianitaFachrul dkk, 2008). Intensitas cahaya secara tidak langsung dapat mempengaruhi kelimpahan makanan zooplankton sendiri yaitu fitoplankton karena membutuhkan cahaya untuk berfotosintesis. Cahaya secara langsung mempengaruhi keberadaan dan adaptasi zooplankton karena secara 
umum zooplankton dominan bersifat fototaksis negatif karena pada siang hari zooplankton akan cenderung turun ke permukaan untuk menghindari predator yang aktif pada siang hari (Wahyuni, 2010).

Menurut pendapat Ruppert (2004) bahwa bagian terbesar zooplankton adalah anggota filum arthropoda. Filum Arthropoda hanya kelas Crustacea yang hidup sebagai plankton dan merupakan zooplankton terpenting bagi ikan di perairan air tawar maupun air laut. Hal tersebut diperkuat oleh pendapat Wickstead (1976) Copepoda salah satu kelas dalam filum Arthropoda mendominasi populasi zooplankton di perairan laut dengan persentase berkisar antara $50-80 \%$ dari biomassa zooplankton dalam ekosistem laut.

Zooplankton dalam bidang perikanan memiliki manfaat khususnya di sektor perekonomian masyarakat karena semua jenis kehidupan ikan berawal dari plankton baik telur maupun larva. Kegiatan penangkapan ikan yang dilakukan pada malam hari dengan rendahnya intensitas cahaya mengharuskan nelayan menggunakan cahaya buatan yaitu lampu untuk membantu penangkapan ikan. Zooplankton membantu dalam menentukan lokasi pemijahan dan penangkapan jenis ikan tertentu. Cahaya buatan yang berasal dari lampu dibedakan menjadi dua intensitas yaitu 2000 lux dan 300 lux. Tujuan dari penelitian ini adalah untuk mengetahui struktur komunitas zooplankton dan mengetahui besar intensitas cahaya yang optimal dalam penangkapan ikan berkaitan dengan kelimpahan zooplankton di perairan Desa Tambakpolo Demak.

\section{MATERI DAN METODE}

Penelitian dilakukan di perairan Desa Tambakpolo, Demak. Materi penelitian meliputi sampel air dan zooplankton yang diambil di lokasi penelitian. Titik penelitian (stasiun) ditentukan menggunakan metode purposive sampling, yaitu pengambilan yang dilakukan berdasarkan pertimbangan serta tujuan tertentu (Andriana, 2017). Lokasi penelitian untuk pengambilan sampel dilakukan 3 stasiun yang berbeda dengan jarak masing-masing stasiun 100 meter (Gambar 1) dan dilakukan sebanyak 3 kali pengulangan di setiap stasiun. Sampel plankton diambil dengan bantuan plankton net dengan 2 perlakuan yaitu dengan cahaya yang berasal dari lampu dengan intensitas 300 lux dan 2000 lux (besaran intensitas cahaya mengikuti lampu yang digunakan oleh nelayan). Jumlah air yang tersaring diperoleh dengan mengalikan jarak diantara dua titik tersebut dengan diameter plankton net. Sampel plankton disimpan dalam botol berlabel, dan ditambahkan bahan pengawet formalin $4 \%$.

Pengukuran parameter fisika dan kimia perairan meliputi suhu, kedalaman, kecerahan, $\mathrm{pH}$, salinitas, DO, dan arus.Penentuan komposisi dan kelimpahan zooplankton ditentukan berdasarkan pencacahan pada Sedwick-rafter Sedgwick-Rafter dengan bantuan buku identifikasi Fukuyo (1981). Nilai kelimpahan yang didapat nantinya dikonversi dengan cara perhitungan kelimpahan zooplankton diperoleh dengan menggunakan rumus menurut Michel (1994) Indeks keanekaragaman dihitung berdasarkan indeks Shannon Wienner (Odum,1993) Nilai indeks keanekaragaman dengan kriteria sebagai berikut jika $H^{\prime}<1,0$ menggambarkan sebaran individu tidak merata (keragaman rendah); $1 \leq H^{\prime} \geq 3,0$ keragaman sedang; $H^{\prime} \geq 3,0$ keragaman tinggi.

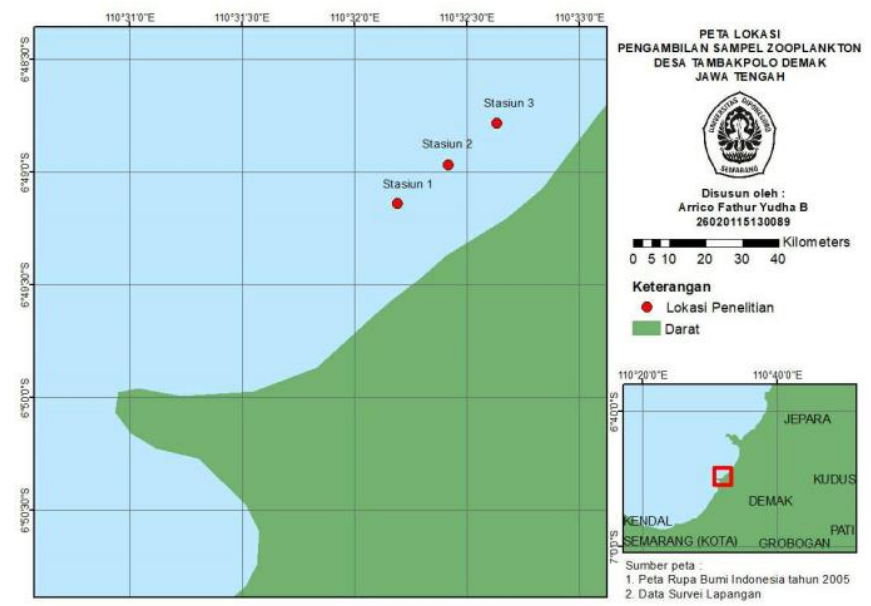

Gambar 1. Peta Lokasi Penelitian 
Indeks keseragaman dihitung dengan rumus (Krebs, 1972) dimana nilai indeks keseragaman dengan kriteria jika $0<E \leq 0,5$ menggambarkan keseragaman rendah; $0,5<E \leq 0,75$ keseragaman sedang; dan 0,75 < E $\leq 1$ keseragaman yang tinggi. Indeks dominansi Simpson (D) menurut Odum (1993), dimana nilai indeks dominansi mendekati 0, maka dapat dipastikan bahwa tidak ada spesies yang mendominasi (struktur komunitas dalam keadaan stabil) sebaliknya apabila indeks dominansi mendekati 1, berarti ada salah satu spesies yang mendominasi populasi tersebut (struktur komunitas labil, karena terjadi tekanan ekologis). Pengujian kelimpahan zooplankton dianalisis dengan uji Non Parametrik Mann Whitney pada program SPSS. Hubungan perbedaan kelimpahan zooplankton pada setiap intensitas dianalisis dengan menampilkan tabel hasil yang dapat menentukan perbedaan tersebut signifikan atau tidak.

\section{HASIL DAN PEMBAHASAN}

Berdasarkan hasil identifikasi tiap stasiun penelitian di perairan Tambakpolo, Demak menunjukan bahwa komposisi Arthropoda yang ditemukan terdiri dari 2 kelas dan 5 genus yaitu Crustacea: Calanus, Paracalanus, Neomysis, Eucalanus dan Candacia; dan Malacostraca: Sergia. Kelas Crustacea khususnya pada subkelas Copepoda terlihat jelas merupakan kelompok yang paling sering dijumpai di setiap stasiun penelitian. Hal tersebut diperkuat oleh pendapat Wickstead (1976) Copepoda salah satu kelas dalam filum Arthropoda mendominasi populasi zooplankton di perairan laut dengan persentase berkisar antara 50-80\% dari biomassa zooplankton dalam ekosistem laut. Genus yang sering banyak dijumpai pada penelitian tersebut selain genus Calanus. Calanus merupakan dalam filum Arthropoda dan kelas Crustacea, dimana genus ini merupakan genus yang paling banyak ditemukan karena salah satunya dia bersifat fototaksis positif terhadap intensitas cahaya dimana saat pengambilan dengan menggunakan cahaya kapal dia merespon aktif terhadap cahaya yang diterima dan dapat bergerak aktif untuk mencari makanannya berupa fitoplankton yang bersifat fototaksis positif juga terhadap intensitas cahaya pada kapal (Ramadhania dkk, 2015).

Berdasarkan hasil kelimpahan total Arthropoda kelimpahan tertinggi berada pada intensitas 2000 lux sebesar 6550 Ind/L dan pada intensitas 300 lux sebesar 4082 Ind/L. Hasil yang didapat dalam perhitungan menunjukan bahwa kelimpahan yang tertinggi pada Stasiun 1 dengan intensitas 2000 lux sebesar 8492 Ind/L dan terendah terdapat pada Stasiun 3 dengan intensitas 300 lux sebesar $2286 \mathrm{Ind} / \mathrm{L}$ (Tabel 1). Hal ini dikarenakan adanya hubungan fitoplankton dan zooplankton yang merupakan hubungan pemakan dan mangsa dalam rantai makanan. Berdasarkan penelitian ini kelas Diatom mendominasi perairan, seperti genus Pleurosigma, Chaetoceros di stasiun 1 dengan kelimpahan sebesar 1959 Ind/L. Arthropoda pada stasiun 1 juga menunjukan nilai kelimpahan tertinggi di perairan Desa Tambakpolo, Demak, sehingga berdasarkan analisis hasil penelitian kelimpahan zooplankton sangat dipengaruhi oleh kelimpahan fitoplankton. Diperkuat oleh penelitian Tambaru (2014), zooplankton akan merespon jika terdapat fitoplankton karena sebagai sumber makanan.

Keanekaragaman, keseragaman dan dominansi merupakan parameter biota yang dapat menjelaskan keadaan indeks ekologi disuatu perairan. Berdasarkan data penelitian, nilai indeks keanekaragaman (H') Shannon \& Weiner (1963) di perairan Tambakpolo, Demak termasuk dalam kategori rendah pada semua stasiun, nilai keanekaragaman berkisar antara 0.03-0.2. Hal ini diduga karena terdapat pengaruh dari kecepatan arus. Kecepatan arus pada perairan Tambakpolo sekitar antara 0,017-0,04 m/s. Menurut pendapat Radiarta (2004), jika arus kurang dari 0,1 m/s termasuk lemah. Hal tersebut diduga karena saat pengambilan sampel dilakukan pada saat musim peralihan sehingga kondisi perairan sedikit banyak dipengaruhi musim timur dengan bercirikan angin, arus dan gelombang laut relatif kecil. Selain itu lemahnya arus di perairan Tambakpolo diduga disebabkan pada malam hari air laut sedang surut sehingga melemahkan arus yang mengalir di perairan tersebut.

Indeks keseragaman berkisar antara 0,04-0,23 dimana menurut Krebs (1972) termasuk dalam kategori keseragaman populasi rendah. Berdasarkan kriteria tersebut, jadi keseragaman Arthropoda di perairan Tambakpolo cenderung memiliki penyebaran yang merata dikarenakan jumlah pada tiap genus tidak terjadi perbedaan yang terlalu signifikan dan dapat dikatakan bahwa keseragaman Arthropoda di perairan Tambakpolo berada dalam keadaan labil 
Tabel 1. Nilai Rata-rata Kelimpahan Arthropoda (ind/liter) Pada Intensitas 300 lux dan 2000 lux

\begin{tabular}{ccccccc}
\hline \multirow{2}{*}{ Stasiun } & \multirow{2}{*}{ Intensitas } & \multicolumn{3}{c}{ Pengulangan } & \multirow{2}{*}{ Rata-rata } & \multirow{2}{*}{ Standar Deviasi } \\
\cline { 3 - 5 } & & 1 & 2 & 3 & & \\
\hline 1 & $300 \operatorname{lux}$ & 8165 & 6859 & 4736 & 6587 & 1731 \\
2 & $300 \operatorname{lux}$ & 5389 & 4409 & 326 & 3375 & 2685 \\
3 & $300 \operatorname{lux}$ & 979 & 3266 & 2613 & 2286 & 1178 \\
\hline 1 & $2000 \operatorname{lux}$ & 11758 & 6532 & 7186 & 8492 & 2847 \\
2 & $2000 \operatorname{lux}$ & 4899 & 10942 & 979 & 5607 & 5019 \\
3 & $2000 \operatorname{lux}$ & 8655 & 7839 & 163 & 5552 & 4685 \\
\hline
\end{tabular}

dan tidak terjadi persaingan perebutan makanan. Menurut Faust (2000), semakin besar nilai keseragaman maka nilai keanekaragamannya juga akan semakin besar dan nilai dominansi berbanding terbalik atau dapat diartikan dapat satu atau beberapa jenis yang sangat melimpah dari jenis lain.

Indeks dominansi Simpson (1949) (C) berkisar antara 0,61-0,97 disetiap stasiun. Nilai tersebut termasuk dalam kategori dominansi tinggi. Indeks dominansi Arthropoda di perairan DesaTambakpolo, Demak. Menurut Simpson (1949) di dalam perairan Tambakpolo terdapat individu yang mendominasi dikarenakan kategori yang ada di perairan tersebut masuk dalam kategori dominansi tinggi $(0,5<\mathrm{D}<1)$ atau mendekati 1 dan kemungkinan terjadi tekanan ekologis. Hal tersebut dibuktikannya dengan sedikitnya variasi dan jumlah jenis yang ditemukan.

\section{KESIMPULAN}

Berdasarkan hasil penelitian bahwa kelimpahan Arthropoda di perairan Tambakpolo, Demak pada intenstas 2000 lux yaitu sebesar 6.550 ind/L lebih tinggi dibandingkan dengan kelimpahan Arthropoda pada intensitas 300 lux yaitu sebesar 4.082 ind/L. Hubungan yang terjadi antara intensitas dan kelimpahan Arthropoda di perairan Tambakpolo tidak terjadi hubungan antara kedua faktor tersebut dengan hasil statistik Asymp sig (2 tailed) $>0.05$ memberikan hasil menolak Ho. Selain itu berdasarkan penelitian, indeks keanekaragaman Arthropoda pada perairan Tambakpolo, Demak adalah rendah. Indeks keseragaman dalam kategori sedang dan ada dominansi.

\section{DAFTAR PUSTAKA}

Faust, M.A. 2000. Dinoflagellate Associations in a Coral Reef-Mangrove Ecosystem: Pelican and Associated Cays, Belize. Atoll Research Bulletin, 473:133-149.

Ferianita-Fachrul, Setijati, H.E., Monika, W. 2008. Komposisi dan Model Kemelimpahan Fitoplankton di Perairan Sungai Ciliwung, Jakarta. Jurnal Biodiversitas. Volume 9, Nomor 4. Halaman: 296-300.

Kusumaningrum, A., Sudarsono \& Suhartini. 2017. Struktur Komunitas Plankton pada Musim Penghujan di Telaga Bromo Kecamatan Paliyan Kabupaten Gunungkidul Yogyakarta. Jogja.

Nontji, A. 2006. Tiada Kehidupan di Bumi Tanpa Keberadaan Plankton. Lembaga IImu Pengetahuan Indonesia, Jakarta.

Nybakken, J.W. 1992. Biologi Laut. Suatu Pendekatan Ekologis. PT Gramedia. Jakarta.

Radiarta, I.N. 2013. Hubungan Antara Distribusi Fitoplankton dengan Kualitas Perairan di Selat Alas, Kabupaten Sumbawa, Nusa Tenggara Barat. Jurnal Bumi Lestari, 13(2):234-243.

Ramadhania, S., Priyanti, Etyn Yunita. 2015. Fitoplankton Sebagai Bioindikator Saprobitas Perairan Di Situ Bulakan Kota Tangerang. Jurnal Biologi Al-Kauniyah. Vol. 3 No. 2.

Ruppert, E.E., Fox, R.S. \& Barnes, R.D. 2004. Introduction to Metazoa. Invertebrate Zoology (ed. 7). Brooks / Cole. 7:103-104.

Wahyuni, Indah. 2010. Struktur Komunitas Dan Kelimpahan Fitoplankton Di Perairan Muara Sungai Porong Sidoarjo. Jurnal Kelautan. Vol.3 No. I. ISSN: 1907-9931. 